\title{
ethic@

\section{A NAÇÃO E A ARENA INTERNACIONAL: DESAFIOS CLIMÁTICOS GLOBAIS}

\section{THE NATION AND THE INTERNATIONAL ARENA: GLOBAL CLIMATE CHALLENGES}

\author{
FABIO ALVES GOMES DE OLIVEIRA ${ }^{1}$
}

\author{
(UFF, Brasil)
}

\begin{abstract}
Discussions about morality and justice in the international arena often, when they reject the realistic theory, end up adopting two possible general positions: communitarian or cosmopolitan. Each one prioritizes different ways of interpreting rights and obligations and has variants. For the discussion proposed here, to understand to which extent national sovereignty makes use of some important assumptions from the communitarian perspective - that we call here defenders of the nation-state - is fundamental to comprehend how the nation-state has been highlighted as the primary actor in international discussions. To do this, we will try to situate this perspective in two moments. Both will have as a guiding line the reading of one of the greatest proponents of this perspective in the current debates on the subject, David Miller. At first, the work "On Nationality" and later "National Responsibility and Global Justice" will be analyzed so that we can identify more deeply the concept of nationality defended by Miller and how he presents himself in the face of current global challenges, his advances and also limits.
\end{abstract}

Keywords: National Borders. Global Climate Change. Moral Obligations.

\section{RESUMO}

Discussões sobre moralidade e justiça no campo internacional frequentemente, quando rejeitam a teoria realista, acabam adotando duas posições gerais possíveis: comunitaristas ou cosmopolitas. Cada qual prioriza diferentes modos de interpretação de direitos e obrigações e possuem variantes. Para a discussão aqui proposta, perceber em que medida a soberania nacional se faz valer de alguns pressupostos importantes da perspectiva comunitarista que, aqui alocada, chamaremos de defensores do estado-nação, é fundamental para compreender o modo como o estado-nação vem sendo destacado como o ator primordial das discussões no âmbito internacional. Para tal, procuraremos situar essa perspectiva em dois momentos. Ambas terão como fio condutor a leitura de um dos maiores defensores dessa perspectiva nos debates atuais sobre o tema, David Miller. No primeiro momento será analisada a obra "On Nationality" e, posteriormente, "National Responsibility and Global Justice" de modo que seja possível identificarmos mais profundamente o conceito de nacionalidade defendido por Miller e como ele se apresenta diante dos desafios globais atuais, seus avanços e também limites.

Palavras-chave: Fronteiras Nacionais. Mudanças Climáticas Globais. Obrigações Morais.

\section{A nação}

David Miller (1997), em sua obra On Nationality, se debruçou quase que exclusivamente na discussão pautada na identidade nacional e na defesa dos vínculos oriundos de uma vida dentro de uma sociedade específica. Desse modo, é travada uma 
discussão filosófica bastante conhecida - a questão da associação direta e/ou a importância dos vínculos particulares dentro de um processo de reconhecimento, de justiça e, claro, de geração de responsabilidades e obrigações. Segundo Conceição Moreira (2005), a identidade nacional dentro desse projeto de Miller é constitutiva da identidade pessoal:

partilhá-la impõe obrigações especiais mútuas e gera uma aspiração à autodeterminação; o ideal seria Estado e nação coincidirem, o que é raro; portanto, nas sociedades contemporâneas é dever do Estado equilibrar o respeito pelas identidades de grupo com o respeito pela identidade nacional, criando uma cidadania comum e limitada, que é condição indispensável para impedir a fragmentação. Esta concepção de cidadania corresponde, segundo o autor, ao ideal da cidadania republicana e seria a mais adequada a uma democracia deliberativa. (MOREIRA, 2005, p. iii)

Em primeiro lugar, Miller aborda a concepção de nacionalidade "como uma espécie de força elementar fora do controle humano, semelhante a fenômenos naturais como maremotos” (MILLER, 1997: 4-5). E ao contrário de uma perspectiva realista, Miller não subscreve qualquer concepção de nacionalidade que defina as nações como totalidades orgânicas, atuando em nome da defesa dos interesses nacionais sem estarem sujeitas a qualquer limite ético. $\mathrm{O}$ autor considera que a nacionalidade, assim concebida, exige de nós um refinamento a respeito de duas formas distintas de compreendermos as possibilidades de se advogar em prol da própria nação: a nacionalidade ocidental e nacionalidade oriental; a primeira seria um tipo de nacionalidade desejável, porque é compatível com os princípios de um estado liberal, a segunda seria indesejável, pois fomentaria o autoritarismo e a repressão cultural (MILLER, 1997: 7-9).

Moreira (2005) afirma que Miller também defende que, embora estas distinções sejam pertinentes, não é certo que sejam operativas, pelo que prefere utilizar o termo nacionalidade em vez do termo nacionalismo. E afirma:

Para ser mais específico, eu devo explorar e defender uma ideia de nacionalidade, que eu tomo para abranger as três proposições interligadas seguintes. A primeira envolve identidade nacional, e afirma que pode ser propriamente parte da identidade de alguém que ele pertença a este ou aquele grupo nacional. (...) A segunda proposição é ética, e afirma que as nações são comunidades éticas. (...) A terceira proposição é política, e afirma que as pessoas que formam uma comunidade nacional em um determinado território têm uma legítima reivindicação de autodeterminação política (...). (MILLER, 1997: 10-11 apud MOREIRA 2005, p. 215). 
Para Moreira (2005), em Miller, (1) a primeira proposição divide-se em duas: (i) as nações existem de fato, e não são entidades fictícias; (ii) defender que a nacionalidade é uma parte de nossa identidade não é defender algo irracional; não se trata aqui de dizer que se deve exigir racionalmente que a nossa identidade pessoal seja constituída pela nossa nacionalidade; tampouco excluir a possibilidade de ter outros tipos de identidades coletivas; trata-se apenas de afirmar que "(...) identificar-se com uma nação, sentir-se inextricavelmente parte dela, é uma forma legítima de compreender o seu lugar no mundo.” (MILLER, 1997: 11 apud MOREIRA 2005, p.215-216).

A autora (MOREIRA, 2005) segue afirmando que (2) A proposição ética consiste em afirmar que cada indivíduo tem obrigações para com os indivíduos com quem partilha a mesma nacionalidade, e que essas obrigações são diferentes e mais amplas do que as que se possui para com a humanidade em geral; isso implica que a ética, nas palavras de Miller, deve levar em conta as fronteiras nacionais e não deve impedir a concessão de benefícios especiais àqueles que vivem dentro da mesma nação, que compartilham histórias, e expressões culturais próprias. (MOREIRA, 2005, p. 216)

Para ela, (3) já a

proposição política da posição de Miller envolve a criação de uma estrutura institucional que permita aos membros da mesma comunidade nacional decidir coletivamente sobre questões que lhes dizem respeito. Miller assinala que não defende a criação de um Estado soberano, pois está convencido de que a autodeterminação nacional pode ser concretizada de outras maneiras. E como veremos, há casos em que essa autodeterminação nacional tem de ser revista, mais precisamente para dar resposta aos direitos igualmente legítimos de outras nacionalidades.” (MOREIRA, 2005, p.216)

Segundo Moreira (2005), Miller compreende que

"as três proposições estão de tal forma interligadas que, por vezes, parecem
formar um círculo, já que é difícil reconhecer a força de uma sem reconhecer a
das outras duas. Em Citizenship and National Identity, Miller (2013: 28)
esclarece esta relação e afirma que, por um lado, a identidade comum apoia a
ideia da nação como comunidade ética e o seu desejo de se autodeterminar; por
outro lado, esta autodeterminação potencial, ou real, da nação reforça as suas
exigências como fonte de identidade e como fonte de obrigação." (MOREIRA,
2005, p.216-217)

A autora (2005) segue afirmando que 


\begin{abstract}
"embora o autor considere que, no conjunto, as três proposições se referem a um conceito de nacionalismo bastante modesto, “(...) ele permanece controverso, e muitas pessoas de disposição liberal ou progressiva estariam inclinados a desafiá-lo." (MILLER, 1997: 12). Miller identifica dois tipos de desafios à noção de nacionalidade por ele defendida: (1) de um ponto de vista filosófico, pode-se afirmar que as identidades nacionais são fictícias (ou comunidade imaginadas, para se usar o termo de Benedict Anderson) e que uma pessoa reflexiva e crítica deve ser cosmopolita; (2) de um ponto de vista político, a recusa do reconhecimento do valor da nacionalidade centra-se nas consequências práticas das lealdades nacionais, ou seja, na convicção de que a ideia de nacionalidade tende a apoiar o autoritarismo político." (MOREIRA, 2005, p.217)
\end{abstract}

Para o desenvolvimento e enfoque deste trabalho, iremos focar nossa investigação sobre o primeiro desafio apresentado por Miller.

\title{
O valor das comunidades imaginadas e não-fictícias: a nacionalidade importa
}

A ideia de nacionalidade em Miller pressupõe a necessidade de esclarecer dois pontos: a distinção entre nação e Estado de um lado e a diferença entre nacionalidade e etnia do outro (MOREIRA, 2005). Segundo a autora (2005)

Miller explica a distinção entre nação e Estado afirmando que o conceito de nação envolve uma comunidade de pessoas que aspira à autodeterminação, politicamente falando; enquanto a ideia de Estado tem de referir-se ao conjunto de instituições políticas que essa comunidade aspira a endossar e participar. E é por essa razão que há Estados multinacionais, há nações que, por motivos históricos, possuem mais de um Estado e há situações em que pessoas da mesma nacionalidade estão espalhadas por diferentes Estados nos quais formam minorias. Sobre o segundo ponto, Miller esclarece a confusão entre nacionalidade e etnia, dizendo que "um grupo étnico é uma comunidade que compartilha a mesma ascendência e características culturais (língua, religião, etc.) que a diferenciaram das comunidades vizinhas". (MOREIRA, 2005, p. 219)

Tendo apresentada uma forma diferenciada de compreensão desses quatro conceitos, Miller (1997) se atenta em distinguir a identidade nacional dos outros tipos de identidade, procurando tornar explícitos os principais pressupostos da comunidade nacional, que para ele podem ser divididos em cinco, de acordo com Moreira (2005):

a) as comunidades nacionais são constituídas por crenças, pois as nações existem quando os seus membros se reconhecem uns aos outros como compatriotas e acreditam que compartilham características relevantes; 
b) a nacionalidade é um tipo de identidade que materializa uma continuidade histórica. Para o autor, contrariamente aos grupos que mantêm uma relação pessoal, as nações são comunidades que remontam a um passado remoto e se projetam no futuro, de tal forma que o trabalho e o sangue dos antepassados que construíram a nação cria nos herdeiros a obrigação de darem prosseguimento com uma espécie de 'tarefa' (Miller, 1997: 23-24, apud Moreira, 2005, p. 220);

c) a identidade nacional é ativa, porque as nações fazem coisas em comum, tomam decisões, alcançam resultados. É essa atividade que as torna aquilo que são e as distingue de outras comunidades, cuja identidade é essencialmente passiva;

d) a identidade nacional implica uma ligação entre a comunidade nacional e o território que ela habita: a sua pátria. Para Miller, este elemento territorial não somente auxilia a distinguir as nações de outros tipos de comunidades, como também engendra a conexão entre nações e Estados, pois o que define o Estado é precisamente o direito ao exercício da autoridade sobre determinado território;

e) finalmente, a identidade nacional seria um conjunto de características comuns, uma cultura pública comum, que se traduz no compartilhamento de valores, gostos e sensibilidades.

Neste sentido, Moreira (2005) afirma que

sendo verdade que as nações não se baseiam em relações pessoais, tampouco se baseiam em relações de parentesco, Miller (1997) defende que aquilo que as mantém unidas são as crenças, “(...) mas essas crenças não podem ser transmitidas a não ser através de artefatos culturais que estão disponíveis para todos que pertencem livros, jornais, panfletos, e mais recentemente, a mídia eletrônica." (MILLER, 1997: 32 apud MOREIRA, 2005, p. 223). Para o autor, essa é a base que assenta a concepção de que nações podem ser definidas enquanto comunidades imaginadas, mas não enquanto invenções ilegítimas, já que a existência delas depende de atos de imaginação coletiva que se exprimem através dos meios de comunicação; sendo, portanto, os meios de comunicação extremamente relevantes para a manutenção ou até mesmo a persistência (existência) do imaginário coletivo que caracteriza as nações. (MOREIRA, 2005, p. 223) 
Outra preocupação do autor é determinar se a identidade nacional é ou não predominante sobre a pessoal. Para Miller as lealdades nacionais têm precedência absoluta sobre todas as outras, argumentando que ter uma identidade nacional não é o mesmo que ser nacionalista em sentido doutrinário; a nacionalidade é, de fato, um dos ingredientes da identidade e, por isso, as pessoas vivem conflitos internos quando se coloca a necessidade de optar entre a lealdade nacional e outras lealdades. E é dessa maneira que Miller defende que ter uma identidade nacional implica ter obrigações especiais para com os restantes membros da mesma nacionalidade, obrigações essas que não se possuem para com os outros humanos.

\section{As fronteiras das obrigações segundo David Miller}

Miller nomeia de universalismo ético aquelas perspectivas que concebem o homem como indivíduo independente e anterior às suas relações com os outros homens; deste ponto de vista, apenas os fatos gerais acerca dos outros indivíduos poderiam servir para determinar as obrigações para com eles, embora seja legítimo justificar uma ação baseada em fatos relacionais com recurso a princípios universais. (MILLER, 1997, p.50)

O particularismo ético, para Miller, seria aquela posição que defende que as relações entre as pessoas constituem algo que deve ser apreendido nas circunstâncias daquele espaço e tempo. Segundo essa perspectiva, o sujeito da ação é sempre alguém que tem uma multiplicidade de laços e compromissos com outros sujeitos, grupos e coletividades; e tais laços e compromissos não podem ser simplesmente ignorados no ato da geração de responsabilidades morais e políticas.

Assim, atuar de certa forma em relação a uma pessoa com quem você mantém algum vínculo especial - uma mãe, um amigo, um irmão, um namorado - geraria compromissos específicos da mesma maneira. É dessa forma que Miller entende que o fato de todos os indivíduos possuírem distintas formas de relações, cada uma delas lhes coloca exigências diversas e não há uma única perspectiva particular que abarque todas dentro de um mesmo universo de hierarquia - são universos diferentes e merecem enfoques distintos.

Dessa forma, para uma perspectiva universalista, a ideia de deveres associativos (particularistas) apareceria como uma rendição da razão a um conjunto de fatores 
outros, como o apelo ao sentimento e até mesmo ao preconceito e às convenções contingentes (MILLER, 1997). Como contraponto, Miller afirma categoricamente a sua opção pelo particularismo ético de modo que o mesmo seja compreendido como um conjunto de lealdades que só podem ter significados intrínsecos, adotados a partir da constatação de vínculos particulares, dentro de uma nação.

Miller prossegue dizendo que:

Uma resposta melhor é que semelhanças culturais significam que os co-nacionais estão mais bem informados uns sobre os outros do que sobre pessoas de fora, e, portanto, em melhor posição para dizer, por exemplo, quando seus companheiros estão em necessidade, ou privados de seus direitos. Isso, penso eu, é o argumento mais forte que pode ser dado, de um ponto de vista universalista, para reconhecer obrigações especiais a compatriotas. (MILLER, 1997, p.63)

É dessa maneira que Miller lança mão de um projeto que poderíamos nomear de uma "ética de deveres associativos" aplicada às nações, podendo ser compreendida como um afastamento de uma concepção cosmopolita. Mas como uma comunidade imaginada (concepção aceita por Miller ao se conceituar uma nação) pode gerar responsabilidades especiais?

Não obstante reconhecer que não atingiu o objetivo de demonstrar que as responsabilidades e obrigações éticas dos membros de uma nação derivam de seu pertencimento à comunidade nacional, Miller afirma que isso não implica que tais obrigações sejam meramente subjetivas, pois a cultura seria um fenômeno público e qualquer indivíduo poderia ser capaz de interpretar correta ou incorretamente as obrigações e responsabilidades que dele derivam. Mais ainda, o fato da cultura pública ser um produto do debate político, não implica que, a curto prazo, ela seja facilmente manipulável pelos atores políticos; muito pelo contrário, o autor está convencido de que, geralmente, a cultura pública é bastante resistente.

Para Miller, esta dimensão ética da nacionalidade implica duas grandes diferenças entre a comunidade nacional e as comunidades menores. Em primeiro lugar,

A potência da nacionalidade como fonte de identidade pessoal significa que suas obrigações são fortemente sentidas e podem se estender até muito longe - as pessoas estão dispostas a sacrificar-se por seu país de uma forma que não estão por outros grupos e associações. (MILLER, 1997, p.70). 
Em segundo lugar, há que se reconhecer que as obrigações impostas pela nacionalidade têm caráter especial que exige que se faça a análise do que acontece quando as fronteiras nacionais coincidem com as fronteiras dos Estados. Segundo o autor, são enormes as vantagens da sobreposição entre direitos de cidadania e direitos de nacionalidade: quando a nação se identifica com o Estado, os direitos de nacionalidade podem ser realizados através do Estado, contribuindo para que se fortaleçam; tal sobreposição também é benéfica para os direitos e as obrigações de cidadania, que passam a basear-se na reciprocidade difusa que caracteriza a comunidade nacional, a qual passa a integrar elementos redistributivos.

\section{A nação e o mundo: limites e responsabilidades}

Na obra "National Responsibility and Global Justice", Miller (2007) desenvolve uma perspectiva que associa sua defesa do compromisso nacional para com seus conacionais de um lado e, de outro, a obrigações para com os problemas globais. Para essa avaliação, Miller analisa o problema a partir do que ele chama de argumento positivo e argumento negativo.

De acordo com o argumento positivo, membros de uma mesma nação deveriam ser responsáveis coletivamente pelas ações que sua nação realiza, incluindo ações passadas e que ainda promovem algum tipo de consequência. Ou seja, conacionais compartilhariam os benefícios e malefícios das ações realizadas por sua nação, ora respondendo, ora representando. Compreendendo a responsabilidade dessa maneira, uma nação não poderia ser responsabilizada ou se sentir responsável por consequências de ações de que ela não participou em um nível internacional. Miller diferencia esses dois polos da responsabilidade - local e global - na tentativa de também localizar uma distinção importante: o debate entre a justiça social e a justiça global, respectivamente.

Essa associação se dá porque Miller está preocupado com que o debate sobre a justiça global acabe minando algumas responsabilidades que, para ele, são caras ao seu projeto em prol da nacionalidade. Miller crê que os Estados-nação estão prioritariamente comprometidos com a necessidade de fazer justiça social. Desse modo, o enfoque dado ao compromisso global, se sobrepondo aos desafios e exigências nacionais, desvaloriza o fato de que, ao abdicar do exercício da sua autodeterminação, a nação pode ficar impedida de praticar a justiça social; e as nações impedidas de exercer 
a autodeterminação também podem ser impedidas de praticar a justiça entre os seus membros.

O autor crê também que é errado afirmar que não existe qualquer conflito entre os dois tipos de justiça. Além disso, Miller chama atenção para uma interpretação que, segundo ele, é equivocada, mas disseminada, pois percebe a justiça global enquanto uma espécie de justiça social levada a uma escala maior. Para Miller, não se trata de uma mera diferença de escalas, porque, sendo as concepções de justiça diferentes em diferentes contextos culturais, a forma como as nações procuram satisfazer as exigências de justiça social também é diferente. A razão é que tais concepções fazem parte de algo mais vasto, isto é, de uma visão de mundo expressa por toda a cultura da sociedade a que se pertence. Assim, apesar da globalização, as culturas diferem umas das outras e, consequentemente, também as concepções de justiça.

Se os argumentos que eu dei para ver nações como os locais ideais para a democracia deliberativa em grande escala são válidas, e se também é verdade que a democracia deliberativa ajuda que uma concepção compartilhada de justiça social surja e seja implementada, então temos boas razões para favorecer os Estados-nação como formas de organização política. (MILLER, 2007)

Dentro da comunidade nacional, portanto, a justiça deve assumir a forma de uma concessão igualitária de direitos legais e dos outros benefícios decorrentes do seu pertencimento. Mas os direitos e recursos a distribuir dependem da comunidade daqueles a quem eles são distribuídos. Neste caso, o autor considera que a existência de direitos diferentes só é injusta dentro de um determinado Estado, pois significa falta de reconhecimento e respeito, logo possuiria um estatuto diferenciado.

Para Miller, todas as culturas políticas nacionais possuem um conjunto de entendimentos partilhados que constituem o contexto fundamental dos princípios da justiça e que fazem da comunidade política nacional o campo de aplicação da justiça social. Dentro do Estado-nação, existe um acordo acerca da base sobre a qual as pessoas podem exigir recursos e avaliar os recursos distribuídos. Assim, são os padrões comuns de avaliação que permitem formular juízos sobre as necessidades individuais, calcular o que um indivíduo merece, ou determinar se há direito a uma distribuição equitativa de recursos.

As decisões dos diferentes governos relativamente a questões como a escolha de um sistema econômico, o tipo de proteção social a ser proporcionada pelo Estado, a taxa 
de crescimento ou declínio populacional, a imposição de códigos religiosos de comportamento e o tipo de relação com o meio ambiente afetam os tipos e a quantidade de recursos a que os indivíduos têm acesso.

Contra a posição de Miller, os defensores da justiça global cosmopolita, tais como Simon Caney e Thomas Pogge, argumentam que é possível exigir a eliminação das desigualdades em nível global. Aqui iremos nos ater às críticas advindas de Simon Caney, conforme se segue.

Caney dirige sua crítica à concepção de identidade nacional defendida por Miller, pois acredita que ela carrega em si mesma uma projeção internacional que justifica o modo como o território para além das fronteiras nacionais se comporta. Para Caney, é por uma compreensão restritiva de afiliações que as diretrizes internacionais rejeitam o compromisso global que paira nesse território, reproduzindo injustiças em diversos âmbitos.

Em Justice without Borders, Caney defende que os princípios comparativos da justiça distributiva podem aplicar-se ao nível transnacional e oferece como exemplos as políticas agrícolas e de pescas comuns dentro da União Europeia, a atuação de certas instituições internacionais, como a ONU, o Banco Mundial e o Fundo Monetário Internacional (FMI), as intervenções humanitárias, as políticas ambientais e as políticas para os refugiados políticos e religiosos e vítimas de discriminação em diferentes níveis. Caney (2005b) tenta demonstrar que é falsa a tese defendida por Miller, segundo a qual os indivíduos só podem ser analisados, em termos de justiça dentro das nações. Caney também levanta dúvidas em relação à convicção de que é impossível aplicar quaisquer desses princípios fora das afiliações particularistas. Para Caney, David Miller é um expoente da concepção comunitarista de associação por atribuir um componente identitário, um componente cultural e um componente motivacional à defesa da nação (e nacionalidade).

Caney (2005b) tenta questionar essa compreensão de nacionalidade oferecendo como exemplo os indivíduos que são oriundos dos Estados europeus, mas não se identificam enquanto europeus, pois não conseguem pensar numa comunidade europeia enquanto uma real comunidade. Na percepção de Caney, isso significa dizer que os princípios comparativos se aplicam muitas vezes para além das fronteiras nacionais estabelecidas pelo dever associativo pretendido em Miller, e caminham fora da comunidade. 
Outro aspecto que merece consideração tem a ver com a própria noção de justiça. Para Caney, a imparcialidade que orienta as concepções de justiça fica prejudicada e impacta diretamente nas discussões globais. Caney (2005b) se preocupa com os componentes particularistas que podem orientar de modo injusto as decisões tomadas no campo internacional. Sendo assim, ao contrário do que Miller endossa, Caney acredita que o pertencimento cultural não deveria ter qualquer influência no exercício da justiça em fóruns sobre questões globais. É claro que aqui poderíamos dizer que, de fato, a justiça não precisa ser cega, tampouco imparcial, mas simplesmente admitir que a crítica de Caney cabe à Miller nessa dimensão.

A questão aqui é que Miller compreende que todas as obrigações impostas pelos requisitos da justiça global cosmopolita limitarão a autodeterminação nacional dos respectivos Estados. Fica a questão em aberto se, de fato, a adoção de uma perspectiva cosmopolita necessariamente implica na diminuição da autodeterminação nacional. Pensamos que isso não precisa ser compreendido dessa forma, conforme veremos com maiores detalhes nas seções subsequentes. Entretanto, é preciso sinalizar que, de alguma maneira, a soberania nacional entra em discussão à medida que pretendemos pensar os impactos negativos que uma concepção de nacionalidade, e a responsabilidade que ela carrega, pode impactar negativamente nas decisões que são tomadas em território internacional, sobre assuntos que transcendem tais fronteiras e afiliações.

De toda forma, ao que parece, a justificativa do pertencimento a uma determinada nação como atributo moral capaz de guiar nossos compromissos parece indispensável para o debate sobre os problemas globais. Afinal, seriam as nações moralmente comprometidas com os interesses de seus conacionais mesmo quando esses interesses estão em conflito com os demais interesses de estrangeiros? Feito esse questionamento, veremos a seguir de que modo a moral que subjaz a perspectiva de Miller impacta nas discussões sobre as mudanças climáticas e, posteriormente, como influencia direta ou indiretamente no modo como o sistema vigente das relações internacionais propõe soluções para esse problema de causa local, mas de impacto global.

\section{A responsabilidade nacional e os impactos sobre o debate climático²}

Em National Responsibility and International Justice, David Miller (2004) expõe de forma bastante clara o motivo pelo qual acredita que os vínculos que emergem de 
uma comunidade - políticos, sociais ou culturais - criam deveres também especiais de preocupação e garantia de interesses. Neste texto, David Miller traça um diálogo próximo com Richard Miller ${ }_{2}$ de modo a considerar de que forma é preciso e desejável balancear as preocupações e interesses nacionais com as necessidades internacionais. Entretanto, os interesses advindos desses vínculos especiais são sempre, para ambos os autores, sobrepostos aos demais.

De modo geral, a moral que inclui a proximidade e seus vínculos como ingredientes presentes em sua formulação, tal qual a defendida por David Miller (2004) e Richard Miller (2004), expressa uma tentativa de garantir que as bases da moralidade considerem os compromissos que são criados com aqueles que mantêm alguma proximidade conosco, justificando, portanto, uma hierarquia de responsabilidade baseada em deveres associativos. Como percebemos em seções anteriores, para David Miller, o pertencimento a uma comunidade específica é um elemento que deve ser levado a sério nas discussões morais acerca da responsabilidade. Em suma, trata-se de defender a ideia de que relações especiais produzem responsabilidades na mesma proporção.

Entretanto, devemos nos perguntar se a defesa de uma noção de responsabilidade limitada ou, no mínimo, hierarquizada pelo pertencimento a uma nação seria adequada no debate ambiental mais recente, como é o caso das mudanças climáticas. De que modo essa perspectiva centrada nos compromissos com os "seus" conacionais poderia ser compreendida, inclusive, como uma atitude imoral quando alocada nas discussões climáticas globais? Não seria a justiça climática almejada uma perspectiva que precisa justamente enfrentar a responsabilidade restritiva assumida pelos organismos internacionais?

Todos os esforços internacionais para lidar com as mudanças climáticas poderiam ser avaliados como adequados ou inadequados, dependendo do modo como enxergamos a melhor configuração possível para a arena internacional e as relações que são estabelecidas nesse espaço. Se formos levar a sério as recentes tentativas de lidar com o problema das mudanças no clima da Terra, podemos suspeitar de que tais esforços não têm sido tão bons como deveriam ou se almejava ser. O passado, o presente e a previsão futura de emissão de gases de efeito estufa na atmosfera demonstram a seriedade do problema da mudança climática e o caráter indispensável de uma solução urgente e mais precisa para esse caso. 
Apesar das inúmeras promessas contidas nos acordos internacionais para mudanças climáticas, projetadas, em grande parte, para angariar a participação de mais Estados, não se conseguiram mudanças substanciais no comportamento dos mesmos no que diz respeito à dimensão do problema. Trata-se de um problema comum a todos, embora afete distintamente as diferentes partes envolvidas. Em Collective Action on Climate Change, Paul G. Harris (2007a) destaca que o grande desafio das mudanças no clima se dá justamente em função de uma mentalidade presente nas relações internacionais, que ele chama de "you-go-first" (você primeiro). Harris diz que essa é uma mentalidade preponderante entre a maioria dos Estados quando se trata de questões globais, o que resulta, no caso climático, em cortes modestos na emissão de gases do efeito estufa, para não mencionar o contínuo aumento dessas emissões por parte dos países em desenvolvimento. Harris chega a dar o exemplo da plena implementação do Protocolo de Kyoto e destaca que mesmo ele resultaria em redução de bem menos de cinco por cento das emissões das partes, porque a maneira pela qual os países são autorizados a cumprir os seus compromissos, muitas vezes, não resulta em cortes reais significativos. O que significa dizer que, mesmo que houvesse a implementação plena de certos acordos internacionais, os mesmos não se equiparariam à dimensão do problema a ser enfrentado ${ }^{3}$. Logo, o que podemos suspeitar é da existência de um problema estrutural que impede que as mudanças climáticas sejam compreendidas e, com isso, sejam propostas soluções adequadas. E, na medida em que a mudança climática é percebida como um fenômeno, e que seu enfrentamento se dá pela via da redução das emissões de gases de efeito estufa, ou mitigação do aquecimento global futuro, pensar a reversão desse fenômeno a partir da adoção de novos estilos de vida e, até mesmo, de uma ampliação daqueles que consideramos integrantes de nossa comunidade moral, parece distante. Em termos de dados concretos, para a estabilização das concentrações de gases de efeito estufa na atmosfera seriam exigidos cortes maciços de, no mínimo, oitenta por cento abaixo dos níveis atualmente aceitos (SPETH, 2008, p.29). Alguns cientistas (MATHEWS e CALDEIRA, 2008) chegam a sustentar a tese de que é preciso que as emissões de dióxido de carbono na atmosfera cheguem a zero ${ }^{4}$. Mas em que sentido, mais especificamente, a perspectiva nacionalista interfere nas possíveis soluções climáticas globais?

\section{Causalidade e responsabilidade na arena internacional: desafios climáticos}


Se pensarmos que boa parte das concepções de justiça propostas para o plano internacional (como pensa Miller) é baseada em algum nível de causalidade e responsabilidade (em que aquele que não causou um dano ambiental, por exemplo, não deve pagar por ele), faz sentido o modo como as soluções são propostas para esse cenário. Dentro de um contexto internacional, Henry Shue (1995) defende que

[a] obrigação de restituir àqueles a quem se tenha prejudicado é reconhecida até mesmo por aqueles que rejeitam qualquer obrigação geral de ajudar estranhos. [...] Uma pessoa deve virtualmente sempre restituir, na medida do possível, qualquer um que tenha prejudicado porque alguém deve ainda mais fundamentalmente não causar mal, em primeiro lugar (SHUE, 1995, p.386)

A atribuição de obrigação sublinhada por Shue dentro de um cenário internacional em que a divisão do mundo entre ricos e pobres e a responsabilidade associada à essa divisão econômica polarizada está presente, então parece fazer sentido que todos esses marcadores devam ser considerados para uma compreensão mais aprofundada da relação que é estabelecida entre os Estados no cenário internacional. Afinal, de acordo com Brown (1992),

Se for o caso de que a pobreza dos países/pessoas pobres é o resultado de ações de países/pessoas ricos, então parece ser prima facie um forte caso de se dizer que os últimos têm uma clara responsabilidade de agir de forma a fazer reparações. (BROWN, 1992, p.159)

Em termos de Estados, não há desacordo ao se defender a ideia de que os países industrializados possuem uma responsabilidade histórica sobre o aquecimento global e, portanto, sobre as mudanças no clima. De acordo com Speth (2008), com apenas vinte por cento da população mundial, os países desenvolvidos (industrializados) produziram 3/4 das emissões de carbono, beneficiando-se economicamente como consequência desse processo (SPETH, 2008, p.28) ${ }^{5}$. Os Estados Unidos da América do Norte, com apenas $1 / 20$ da população mundial, emitia, na ocasião, 1/4 dos gases de efeito estufa na atmosfera $^{6}$. Portanto, se aceitarmos a premissa de que os países mais ricos são, de fato, responsáveis pela desproporcionalidade da poluição global, o debate pode simplesmente se dirigir para uma questão prática, ainda que difícil de ser respondida: quais ações iremos adotar para solucionar esse caso? 
O princípio básico mais conhecido é o famoso "o poluidor paga" (polluter-pays). Tal princípio foi acordado entre os países-membro da Organisation for Economic Cooperation and Development (OECD) ${ }^{7}$, em 1972, em que ficaram estabelecidas as bases para suas respectivas políticas ambientais. No contexto internacional, a causalidade e a responsabilidade sugerem que esse princípio (o poluidor paga) deve ser aplicado entre comunidades nacionais, e não somente no âmbito doméstico de cada qual. Entretanto, de acordo com Jamieson (2005), o modo como a arena internacional interpretou e aplicou esse princípio às mudanças climáticas pode ser caracterizado da seguinte forma: "As an instance of the polluted pay principle: polluters benefit from their pollution, while those suffer from the pollution bear the costs" (JAMIESON, 2005, p.168).

De certa forma, isso demonstra a dificuldade de se determinar responsabilidade quando estamos lidando com questões ambientais, especialmente quando estamos abordando questões complexas, como é o caso das mudanças climáticas. Ainda que concordemos que os países mais ricos mereçam ser considerados os maiores culpados, (por diversas razões, mas, sobretudo pelo trajeto histórico de industrialização benefício ao longo da história da formação das sociedades industriais) destacar qual deles causou danos e quanto causou a outros países, sendo esses mais pobres - e até mesmo a outros países ricos - é uma tarefa delicada, especialmente se consideramos o aumento gradual e significativo da emissão de gases de efeito estufa de países que, dentro dessa escala, são considerados pobres.

Shue (1992) defende a ideia de que os países mais pobres não estão moralmente comprometidos em sacrificar, de nenhuma forma, o ritmo e/ou a extensão dos seus respectivos modos de desenvolvimento econômico para ajudar a prevenir as mudanças climáticas, pois elas são fruto do processo de industrialização que enriqueceu outros países. Vanderheiden (2008) é bastante preciso ao destacar que os países mais responsáveis pela emissão de gases de efeito estufa e, consequentemente, os "culpados" pelos efeitos danosos das mudanças climáticas são os países mais bem preparados para enfrentá-las. Isso tudo nos faz destacar a complexidade do tema proposto, e que, de certa forma, a conjuntura internacional baseada em causalidade e responsabilidade faz emergir a suspeita de que os danos causados por alguns e sofridos por outros fazem das mudanças climáticas um debate acerca das (in)justiças no plano internacional, caracterizando a possibilidade de conceituarmos um novo regime climático e, consequentemente, uma justiça climática efetivamente global. 


\section{As mudanças climáticas globais e os interesses nacionais: responsabilidade comum, mas diferenciada}

Assim como outros tantos acordos ambientais internacionais, aqueles que buscam lidar com o fenômeno da mudança climática se apoiam em "normas vestefálias", tais como: a soberania dos Estados e os direitos dos Estados. Isso significa dizer que o processo de tentar entender as soluções climáticas e propor soluções tem sido guiado em grande parte pela doutrina de uma justiça internacional ambiental sustentada pela noção de resguardo dos interesses nacionais. Normas, discursos e pensamentos associados com a doutrina centrada no Estado têm levado a política internacional e, sobretudo, a diplomacia a concretizar poucos avanços no debate das mudanças climáticas. Ou seja, os problemas que vêm impedindo avanços mais efetivos em outras negociações ambientais também impregnam as ações domésticas e internacionais que buscam responder às mudanças do clima, em nome, quase sempre, da proteção dos interesses nacionais. Por essa razão, o foco nos direitos e interesses dos Estados ocupa lugar de destaque na agenda das mudanças climáticas desde 1992, quando a convenção do clima no Rio de Janeiro aconteceu, posteriormente passando pelo protocolo de Kyoto, negociações diplomáticas e tantos outros acordos subsequentes.

Ainda que boa parte das nações consideradas ricas (sobretudo na Europa) tenha iniciado um processo de redução das emissões de gases de efeito estufa, de acordo com os cientistas do clima, esses avanços ainda estão muito longe do necessário para uma real solução do enfrentamento dos efeitos das mudanças climáticas ${ }^{8}$. Aliás, isso se torna especialmente difícil se considerarmos o modo como a economia global se configurou e prevalece, produzindo um dinamismo de mercado que faz com que os países em desenvolvimento tentem se incluir nesse território que exige deles um crescimento que está automaticamente vinculado a um tipo de produção que, paralelamente, eleva a emissão de gases na atmosfera. Além disso, é preciso destacar que nesses países em desenvolvimento - para citar o Brasil e China - a população que consegue sair da pobreza e torna-se potencial e/ou realmente consumidora adota um estilo de vida que sustenta o modo de economia descrito anteriormente, um modelo prejudicial sob o ponto de vista ambiental. Novamente, parece fundamental que o debate sobre as mudanças climáticas não recaia numa divisão entre países ricos e pobres. 
De acordo com o direcionamento proposto pelo sétimo princípio das Nações Unidas, enquanto os Estados são responsáveis pelos problemas ambientais globais, alguns são mais responsáveis que outros.

Os Estados devem cooperar num espírito de parceria global para conservar, proteger e restaurar a saúde e a integridade do ecossistema da Terra. Tendo em vista as diferentes contribuições para a degradação ambiental global, os Estados têm responsabilidades comuns, porém diferenciadas. Os países desenvolvidos reconhecem a responsabilidade que lhes cabe na busca internacional do desenvolvimento sustentável, tendo em vista as pressões exercidas por suas sociedades sobre o meio ambiente global e das tecnologias e recursos financeiros que controlam. (UNITED NATIONS, 1993, principle 7)

Segundo Stone (2004), o princípio da responsabilidade comum, mas diferenciada, se apoia na ideia de que há interesses comuns a serem considerados entre todos os participantes da arena internacional, mas que esses interesses devem ser pensados de maneira também individualizada, respeitando os interesses dos Estados. Essa dicotomia entre os interesses particulares dos Estados e a defesa de que todo ser humano necessita de uma atmosfera saudável para sua sobrevivência influenciou a decisão da ONU em reconhecer o clima da Terra como um objeto de "interesse comum" a toda humanidade. Isso implicou não só na necessidade de cooperação internacional para proteger esse interesse humano, mas também destacou seu status diferenciado, na medida em que enfatizou os potenciais perigos subjacentes ao problema do aquecimento global que um sistema internacional deve ser capaz de reconhecer para a sobrevivência da humanidade como um todo (BIERMANN, 1996).

Diante de tudo isso, é preciso levar em consideração, na discussão sobre as mudanças climáticas, que o panorama do mundo político atual considera a arena internacional como um território formado por Estados soberanos. De acordo com a "moralidade" (morality of States) que se instaura nesse território (baseada, em grande parte, nos deveres associativos) e a responsabilidade que se revela a partir dela, os Estados devem arcar com o ônus de não violar os direitos do outro Estado. Isso quer dizer também que os Estados mais ricos não possuem uma real obrigação moral de reduzir as emissões de gases de efeito estufa na atmosfera, tampouco de prestar ajuda aos países mais pobres que já sofrem e irão sofrer ainda mais com os efeitos das mudanças climáticas. Ao mesmo tempo em que os Estados reconhecem a importância de uma justiça internacional que possa mediar as relações nesse contexto, no caso das 
mudanças climáticas, o fracasso de implementação dessas diretrizes aparece de forma surpreendente.

A resposta às mudanças climáticas tem pressuposto os direitos dos Estados - o direito de escolha voluntária de como cada qual resolve definir como irá se engajar e participar das ações coletivas internacionais que tratam desse problema. Dentro desse modelo, o debate sobre direitos e deveres dos indivíduos e suas responsabilidades frente às questões globais tem desempenhado um papel bastante secundário, para não dizer nulo. Assim como Simon Caney $\left(2005^{\mathrm{a}}\right.$, p.73) aponta o princípio da "responsabilidade comum, mas diferenciada", referindo-se às responsabilidades dos Estados, destacando e, por vezes, reduzindo a análise à discussão sobre a relação política entre países ricos e pobres.

Sendo assim, são os Estados que ocupam os lugares de atores principais na discussão sobre as mudanças climáticas9"; é a partir dessa eleição que a arena internacional se configura e delibera sobre as possíveis soluções para esse problema. De certa forma, trata-se de permanecer dentro de um cenário onde os limites morais estabelecidos pelo sistema internacional de Vestefália, em 1648, prevalecem. Nesse modelo priorizado, o mundo é composto por Estados-nação. É possível, portanto, questionar em que medida essa configuração não prejudica e/ou limita as possibilidades de pensar alternativas para lidar com as mudanças climáticas. Longe de facilitar a busca por soluções dos problemas ambientais, a hipótese aqui levantada é a de que o sistema internacional, tal qual está organizado atualmente, inviabiliza a consideração de elementos, atores e ações importantes para o debate acerca da moralidade que pode ser pensada para esse território, revelando as responsabilidades que devem ser assumidas e a justiça ambiental que pode ser exigida. Tal debate exige esforços que vão desde a defesa de uma ética e comunidade moral expandida - como propõe o filosofo Peter Singer (2004) em sua obra Um Só Mundo: A Ética da Globalização, até um projeto politico que viabilize a aplicação de um conceito de justiça global que tenha condições de garantir a igualdade em território internacional e, em um só tempo, a autonomia de seus respectivos partícipes. 


\section{Conclusão}

Não faltam acordos internacionais para todos os tipos de questões ambientais, incluindo, claro, as mudanças climáticas. Mas, como Dower $(2007,172)$ destaca: muitas pessoas ainda não conseguem perceber mudanças significativas para a solução desses problemas. Talvez isso se deva ao modo como pensamos nossas obrigações e responsabilidades; como a ideia de nação e seus deveres associativos foram construídos e, mais, como o regime climático foi estruturado e está consolidado. O ponto é que o foco na responsabilidade nacional, na transferência de tecnologia e até mesmo no número crescente de fundos internacionais para o clima tendem a fortalecer as elites nacionais na mesma proporção em que nada dizem sobre como as mesmas devem se comportar. Além disso, poucos abrem brechas para uma reestruturação daqueles que devem ser o foco principal de preocupação dos efeitos climáticos: os seres humanos e não humanos de diferentes partes do mundo que já sofrem as consequências negativas da alteração climática. Afinal, a migração climática já é um fato que assola a vida de seres humanos e não-humanos em todo o planeta.

Se o sistema internacional vigente possui dificuldades em perceber o indivíduo como sujeito direto de suas decisões políticas (são os Estados que ocupam esse lugar), a possibilidade de incluir os animais não-humanos na agenda de discussão sobre as mudanças climáticas, de modo que a qualidade de vida dos mesmos interfira nas decisões que são tomadas, parece difícil ou até mesmo impossível. Ainda que esse não seja o foco deste trabalho, é importante sinalizar que as arestas referentes à moralidade a serem reparadas vão muito além do que este próprio trabalho aponta.

O que temos atualmente é uma investida maciça em encontros diplomáticos para pensar em alternativas e soluções climáticas, mas pouco destaque sobre aqueles que mais se beneficiam do status quo. Aqui me refiro não aos países ricos, mas às pessoas ricas de todos os lugares que, dado o sistema atual, continuam a se beneficiar - ganhar e lucrar - em cima do modelo internacional atual, geralmente às custas do bem-estar das pessoas mais pobres - também de todos os lugares - e de outros seres sencientes que, neste caso, nem ocupam o lugar de sujeitos morais e de direitos. Trata-se, portanto, de evidenciar o caráter imoral e injusto que prevalece no modo como as políticas internacionais sobre o clima são pensadas e aplicadas, não reconhecendo a responsabilidade moral que recai sobre aqueles que podem e devem modificar seus 
estilos de vida e que se veem protegidos pela condição na qual os problemas globais estão inseridos.

A partir dos dados apresentados na tabela abaixo, é possível perceber, por exemplo, o motivo pelo qual se faz necessário pensar um novo modelo para se lidar com as questões globais referentes ao clima: países em desenvolvimento têm superado os países desenvolvidos em suas emissões nacionais de gases de efeito estufa na atmosfera. Isso significa dizer que o real problema sobre as mudanças climáticas se mantém refém de uma interpretação que divide o mundo entre países ricos e pobres, quando, na verdade, outros fatores se cruzam e merecem atenção.

O ranking publicado pelo Carbon Dioxide Information Analysis Center (2006) demonstrava que alguns países como China, Brasil e Índia já ocupam o topo do ranking dos países que mais contribuíam para a emissão de gases de efeito estufa. Tal cálculo contabiliza também as emissões causadas por mudanças de uso do solo, tais como desmatamento para diversos fins.

\begin{tabular}{|c|c|c|c|c|}
\hline Ranking & País & $\begin{array}{c}\text { MitCO2e } \\
\text { (milhöes de toneladas de } \mathrm{CO}^{2} \text { ) }\end{array}$ & $\begin{array}{c}\% \text { do total } \\
\text { mundial }\end{array}$ & $\begin{array}{c}\text { MitCO2e } \\
\text { (milhöes de toneladas de } \mathrm{CO} 2 \text { ) } \\
\end{array}$ \\
\hline 1 & China & $7.216,20$ & $16.35 \%$ & 5.5 \\
\hline 2 & Estados Unidos & $6.931,00$ & $15.71 \%$ & 23.5 \\
\hline 3 & União Européia & $5.328,70$ & $12.08 \%$ & 10.9 \\
\hline 4 & Brasil* & $2.192,60$ & $4.63 \%$ & 11.5 \\
\hline 5 & Indonésia & $2.045,60$ & $4.64 \%$ & 9.3 \\
\hline 6 & Rússia & $2.027,90$ & $4.60 \%$ & 14.2 \\
\hline 7 & Índia & $1.869,50$ & $4.24 \%$ & 1.7 \\
\hline 8 & Japão & $1.387,40$ & $3.14 \%$ & 10.9 \\
\hline 9 & Alemanha & $1.005,00$ & $2.28 \%$ & 12.2 \\
\hline 10 & Canadá & 808,3 & $1.83 \%$ & 25.0 \\
\hline 11 & México & 695,6 & $1.58 \%$ & 6.7 \\
\hline 12 & Reino Unido & 683,8 & $1.55 \%$ & 11.4 \\
\hline 13 & Coréia do Sul & 609,4 & $1.38 \%$ & 12.7 \\
\hline 14 & Itália & 581,5 & $1.32 \%$ & 9.9 \\
\hline 15 & França & 575,2 & $1.30 \%$ & 9.4 \\
\hline 16 & Austrália & 568,5 & $1.29 \%$ & 27.9 \\
\hline 17 & Irã & 563,6 & $1.28 \%$ & 8.2 \\
\hline 18 & Ucrânia & 495 & $1.12 \%$ & 10.5 \\
\hline 19 & Espanha & 470,9 & $1.07 \%$ & 10.8 \\
\hline 20 & Nigéria & 457,9 & $1.04 \%$ & 3.3 \\
\hline
\end{tabular}

Fonte: World's countries ranked (2006)

Se considerarmos os maiores emissores mundiais apresentados pelo gráfico, é interessante notar que os vinte países selecionados respondiam na ocasião por $77,4 \%$ das emissões globais resultantes da queima de combustível fóssil, uso do solo, desmatamento de florestas, etc. (baseado nas emissões registradas em 2005). 
Observamos, portanto, o crescente aumento da contribuição de países em desenvolvimento na emissão de gases prejudiciais aos impactos advindos da mudança do clima. Além disso, é preciso destacar o poder e influência de algumas empresas nacionais (privadas e/ou públicas) e transnacionais não somente diante das decisões que são feitas em acordos internacionais, mas, sobretudo, nesse cálculo final de impacto.

De acordo com o relatório de 2013 da Carbon Disclosure Project (CDP), duas das cinquenta empresas que mais liberaram $\mathrm{CO}_{2}$ na atmosfera nos últimos quatro anos (2009-2013) são brasileiras. São elas: Petrobras - no setor de energia - e a Vale do Rio Doce - no setor de materiais ${ }^{10}$. Ao fim do relatório, a CDP afirma que essas cinquenta empresas juntas são responsáveis por liberar na atmosfera quase $75 \%$ das emissões de gases de efeito estufa do planeta ${ }^{11}$. Que influência essas empresas possuem sobre os Estados e, de que forma, essa influência não impacta diretamente no modo como os Estados se posicionam diante dos acordos internacionais sobre as emissões de $\mathrm{CO}_{2}$ ?

É claro que convocando um conceito de justiça internacional que, consequentemente, afeta o regime climático atual, a polarização do mundo em países ricos e pobres cria uma aparência democrática, sobretudo se pensamos na "dívida histórica climática" que certos países têm para com outros. Entretanto, é preciso admitir que esse modelo de pensamento não tem oferecido resultados eficazes para lidar com a problemática destacada; não tem oferecido ações necessárias para abordar tanto os níveis de poluição que atingem a atmosfera bem como as consequências sobre aqueles que irão sofrer com essa alteração no clima. Ao mesmo tempo, pode não parecer justo se a China e outros países "menos desenvolvidos" (em desenvolvimento) forem obrigados a assumir as mesmas responsabilidades, no combate às mudanças climáticas, que os EUA e outros países considerados mais desenvolvidos - ricos. Tampouco será justo que pessoas ricas de países em desenvolvimento, e especialmente as elites donas de grandes empresas, que consomem supérfluos e que possuem participação econômica considerável nessas sociedades sejam absolvidas das responsabilidades que as mesmas parecem ter sobre a emissão de gases de efeito estufa na atmosfera, principal ingrediente antropogênico das mudanças climáticas e dos seus efeitos sobre o ecossistema.

Por que uma pessoa pobre, digamos, nos Estados Unidos, deve ser responsabilizada na mesma proporção das pessoas ricas de seu país numa avaliação climática (países desenvolvidos x países em desenvolvimento) para proteger e ajudar tanto os pobres, bem como os ricos da China (ou de qualquer outro país em 
desenvolvimento), especialmente quando esses últimos emitem mais gás de efeito estuda na atmosfera? A crença que prevalece de que os países ricos devem ajudar os pobres, no contexto das mudanças climáticas, e que os primeiros devem cortar drasticamente suas emissões de gases de efeito estufa, permitindo aos demais o aumento de suas emissões, parece ser insuficiente e, de certa forma imoral, ainda que seja moralmente fundamentada a partir de uma perspectiva internacionalista interestadual. A partir dessa crítica, propõe-se que o indivíduo vulnerável passe a ser considerado não a partir de sua nacionalidade, mas a partir das reais condições materiais de existência que o mesmo possui para lidar com as mudanças climáticas ${ }^{12}$. Além disso, a questão da responsabilidade entraria em cena também num nível mais elementar, em que cada qual assumiria para si o compromisso que suas ações (estilo de vida) possuem sobre a extensão transfronteiriça que faz parte dos efeitos climáticos globais. Portanto, refém do modo como a arena internacional está configurada, a dificuldade do regime climático vigente em identificar nos indivíduos uma possibilidade significativa de atuação sobre as mudanças climáticas sugere uma nova forma de se pensar essa arena e as responsabilidades morais e legais que se apresentam nesse contexto.

Se a discussão moral não tem a capacidade de substituir a doutrina internacional vigente, deve, pelo menos, ser capaz de aperfeiçoá-la. É necessário, portanto que um conceito de justiça global oriente a discussão climática em conjunto com a realidade do mundo globalizado. A questão que permanece, qual seja, de quem são os participantes de nossa comunidade moral deve ser destaque nas discussões políticas que visam não somente expandir esse horizonte, mas ultrapassar barreiras que a justiça internacional não consegue - um passo significativo para a discussão aqui proposta, evidenciando a necessidade de uma nova concepção de responsabilidade política ampliada que já parece se instaurar nesse contexto.

\section{Notas}

\footnotetext{
${ }^{1}$ Professor Adjunto de Filosofia da Educação no Departamento de Ciências Humanas da Universidade Federal Fluminense, membro permanente do Programa de Pós-graduação em Bioética, Ética Aplicada e Saúde Coletiva (PPGBIOS) da Universidade Federal Fluminense e Professor Colaborador do Programa de Pós-Graduação em Filosofia (PPGF) da Universidade Federal do Rio de Janeiro. e-mail: fagoliveira@id.uff.br
} 
${ }^{3}$ Os dados locais e globais sobre a emissão contínua de gases de efeito estuda na atmosfera podem ser acessados pelo site: http://www.breathingearth.net/

${ }^{4}$ O projeto "Emissões Zero em 2020" já existe e vem sendo colocado em prática em algumas cidades do mundo. Tal projeto nasceu da constatação de que metas mais ambiciosas são necessárias para que a mudança climática global seja, de fato, estabilizada. A cidade de Melbourne, na Austrália, é uma cidade que pretende alcançar o objetivo, que já está em curso desde 2004, até 2020.

${ }^{5}$ Esses são dados oficiais utilizados pelas das Nações Unidas durante a 50ª edição do GSPUN (Graduate Study Programme of the United Nations), ocorrido em julho de 2012 na cidade de Genebra, Suíça. Na ocasião, participei da elaboração do relatório do Grupo IV: estudos sobre Mudanças Climáticas.

${ }^{6}$ No início do Século XX, a emissão per-capita dos EUA já alcançava dez vezes mais o considerado "permitido" por país.

${ }^{7}$ É uma organização econômica internacional de 34 países, fundada em 1961 para estimular o progresso econômico e o comércio mundial. Ela fornece uma plataforma para comparar experiências de políticas de incentivo, buscar respostas para problemas comuns e coordenar as políticas nacionais e internacionais de seus membros.

${ }^{8}$ A tentativa mais recente de achar um caminho "internacional" para a questão da emissão de gases de efeito estufa na atmosfera se deu menos de um mês após a Convenção do Clima (UNFCCC) de novembro de 2013, com a aprovação do Forest Carbon Partnership Facility (FCPF) do Banco Mundial. Este fundo procura ser mais um esforço para diminuição das emissões provenientes da destruição das florestas tropicais. Pela primeira vez, governos, trabalhando junto com a sociedade civil e o setor privado chegaram ao acordo sobre a forma de financiar e medir a redução de emissões provenientes da destruição das florestas, promovendo iniciativas políticas que estão com o objetivo de proteger as florestas tropicais.

${ }^{9}$ É importante destacar que empresas transnacionais, algumas com poder de influência superior a de alguns Estados, interferem significativamente no modo como o sistema internacional opera.

${ }^{10} \mathrm{O}$ CDP não fornece a classificação dos 50 principais emissores, mas publica os nomes e os países: 16 destas empresas são norte-americanas, seis são do Reino Unido e cinco vêm do Canadá, da França e da Alemanha. Com dois representantes, estão Espanha, Japão e Suíça, além do Brasil, e aparecem com uma companhia na relação Austrália, Itália, Luxemburgo, Holanda, Noruega, África do Sul e Coreia do Sul.

11 Sector insights: what is driving climate change action in the world's largest companies? Carbon Disclosure Project. Global 500 Climate Change Report 2013.

${ }^{12}$ Demais seres também poderiam ser considerados, dependendo da perspectiva a ser adotada.

\section{Referências Bibliográficas}

BARRY, C.; POGGE, T. (org.). Global Institutions and Responsibilities: Achieving Global Justice. Blackwell Publishing. 2005.

BARRY, J. Statism and Nationalism: A cosmopolitan Critique. In: SHAPIRO, I.; BRILMAYER, L. (org.), Global Justice. New York University Press. 1999. p. 12-66.

BAUDRILlARD, J. A Sociedade do Consumo. Edições 70. 2011.

BAUMERT, K.A.; HERZOG, T.; PERSHING, J. Navigating the numbers: greenhouse gas data and international climate policy. World Resources Institute. 2005. 
BODEN, T. MARLAND, G. ANDRES, B. World's countries ranked: total fossil-fuel $\mathrm{CO}_{2}$ emissions. Carbon Dioxide Information Analysis Center. Oak Ridge National Laboratory, 2006. Em: http://cdiac.ornl.gov/trends/emis/tre coun.html (Acessado em: 1 de Fevereiro de 2014)

BUCHANAN, A. Justice, Legitimacy, and Self-Determination: Moral Foundations for International Law. Oxford University Press. 2007.

CANEY, S. Cosmopolitan justice, responsibility, and global climate change. Leiden Journal of International Law, 18. 2005a. p. 747-75.

Cosmopolitan justice, rights and global climate change. Canadian Journal of $\overline{\text { Law }}$ and Jurisprudence, 19/2. 2005b. p. 255-78 [Lexis Nexis Academic:paras 1-57].

CDIAC. Carbon Dioxide Information Analysis Center. http://cdiac.ornl.gov/\#. Acessado em: 30 de Agosto de 2014.

DOWER, N. Sustainability and the right to development. In: ATTFIELD, R.; WILKINS, B. (org.), International Justice and the Third World. , London: Routledge. 1992. p. 93-116.

World ethics. In: CHADWICK, R., Encyclopedia of Applied Ethics. San Diego: Academic Press. 1997. p. 561-70.

ELLIOTT, L. Cosmopolitan environmental harm conventions. Global Society, 20/3 (July). 2006. p. $345-63$.

. Transnational environmental harm, inequity and the cosmopolitan response. In: DAUVERGE, P. (org.), Handbook of Global Environmental Politics. Cheltenham: Edward Elgar. 2005. p. 486-501.

FAO. Food and Agricultural Organisation, Livestock's Long Shadow. Rome: Food and Agriculture Organisation. 2007. http://www.fao.org/docrep/010/a0701e/a0701eOO.htm. Acessado em: 15 de março de 2014.

. Tackling Climate Change Through Livestock: A global assessment of emissions and mitigation opportunities. $2013 . \quad$ Em: http://www.fao.org/docrep/018/i3437e/i3437e.pdf. (Acessado em 26 de Dezembro, 2013).

GLOBAL CARBON PROJECT. Carbon budget and trends 2007, 26 September. 2008. http://www.globalcarbonproject.org/carbontrends/index.htm. Acessado em: 20 de fevereiro de 2014.

HARRIS, P. Ethics And Global Environmental Policy: Cosmopolitan Conceptions of Climate Change . ebook isbn 978085793161 0, 2011 
Common but differentiated responsibility: The Kyoto Protocol and United States policy. New York University Environmental Law Journal, 7/1. 1999a. p. 27-48.

IPCC. Intergovernmental Panel on Climate Change, Climate Change 2007: Synthesis Report. 2007a. http://www.ipcc.ch/ipccreports/ar4-syr.htm. Acessado em: 20 de março de 2014.

IPCC. Intergovernmental Panel on Climate Change, Summary for policymakers. In: IPCC, Climate Change 2007:Impacts, Adaptation and Vulnerability. Cambridge: Cambridge University Press. 2007b. p. 7-22.

IPCC. Intergovernmental Panel on Climate Change, Summary for policymakers. In: IPCC, Climate Change 2007: Mitigation. Cambridge: Cambridge University Press. 2007c. p. 1-23.

IPCC. Intergovernmental Panel on Climate Change, Summary for policymakers. In: IPCC, Climate Change 2007: The Physical Science Basis. Cambridge: Cambridge University Press. 2007d. p. 1-18.

IPCC. Intergovernmental Panel on Climate Change, Climate Change 2001. Cambridge: Cambridge University Press. 2002.

MILLER, D. Social Justice. Oxford: Clarendon Press. 1976. 2007 .

National Responsibility and Global Justice. Oxford: Oxford University Press.

Immigrants, Nations, and Citizenship. Journal of Political Philosophy Special Issue: Philosophy, Politics \& Society Volume 16, Issue 4. 2008.

. On Nationality. Oxford: Oxford Press. 1997.

MILLER, M. A. L. The Third World agenda in environmental politics. In: DORRAJ, M. (org.), The Changing Political Economy of the Third World, Boulder, CO: Lynne Rienner. 1995a.

MOREIRA, C. Will Kymlicka e David Miller: Multiculturalismo, Nacionalismo e Secessão. (dissertação de mestrado em filosofia, Universidade do Minho), 2005. Acessado em: 21 de março de 2013.

POGGE, T. Cosmopolitanism and sovereignty. Ethics, 103. 1992. p. 48-75.

SINGER, P. Ética Prática. Martins Fontes. 2006.

Um Só Mundo: A Ética da Globalização. Martins Fontes. 2004.

Famine, affluence and morality. In: AIKEN, W.; LAFOLLETTE, H. (org.),

World Hunger and Morality, Upper Saddle River. NJ: Prentice Hall. 1996. p. 229-43. 
One World. New Haven: Yale University Press. 2004.

Ethics and climate change: A commentary on MacCracken, Toman and Gardiner. Environmental Values, 15/3. 2006. p. 415-22.

UNFCCC. United Nations Framework Convention on Climate Change. 1992. http://unfccc.int/resource/docs/convkp/conveng.pdf. Acessado em: 08 de março de 2014.

UNITED NATIONS. Declaration of the United Nations Conference on the Human Environment (A/CONF.48/14). New York: United Nations. 1972.

Declaration on the Inadmissibility of Intervention and Interference Intervention in the Internal Affairs of States (A/RES/36/103). New York: United Nations. 1981.

United Nations Convention on the Law of the Sea (A/CONF.62/122 (1982), annex III). New York: United Nations. 1982.

Law of the Sea. New York: United Nations. 1983.

United Nations Conference on Environment and Development, General Assembly Resolution No. 44/228. New York: United Nations. 1989. p. http://www.un.org/documents/ga/res/44/a44r228.htm. Acessado em: 10 de março de 2014.

. Convention on Biological Diversity, Montreal: Secretariat of the Convention on Biological Diversity. New York: United Nations. 1992. http://www.cbd.int/doc/legal/cbd-un-en.pdf. Acessado em: 10 de março de 2014.

Rio Declaration on Environment and Development. In: United Nations, Report of the United Nations Conference on Environment Development, vol. I. New York: United Nations Publications. 1993. p. 3-8.

WMO. Climate Knowledge for Action: A Global Framework for Climate Services Empowering the Most Vulnerable. New York: United Nations. 2001.

WORKING GROUP II OF THE INTERGOVERNMENTAL PANEL ON CLIMATE CHANGE. Climate Change 2001. http://www.grida.no/CLIMATE/IPCC TAR/wg2/010.htm. Acessado em: 20 de março de 2014. 